\title{
The Tunbridge Report and the laboratory
}

The average pathologist will probably have not paid much attention to the Tunbridge Report but if it is generally adopted it will affect to some degree every laboratory in the country that sends reports to hospitals.

\section{GENERAL ASPECTS OF THE REPORT}

'The standardization of medical records' is a report of a subcommittee of the Standing Medical Advisory Committee of the Central Health Service Council for England and Wales. The chairman was Professor R. E. Tunbridge of Leeds: the only laboratory member was the late Professor Douglas Collins.

The discussion of the problems concerned in keeping medical records is admirable, and the main conclusion, that some degree of standardization of hospital medical records is both desirable and possible, is one with which any sensible person who has made an attempt to look at the hospital records as a whole, and not only as it concerns his own isolated laboratory, will agree. The Ministry of Health appears to have accepted the Report without question, and is advising hospital authorities to accept its recommendations if possible by 1 April 1966. The Ministry proposes to print most of the necessary documents centrally to the Tunbridge design. Yet it is to be noted that some of the more controversial designs are omitted from the list of printings, and it may be that the Ministry has given more thought to this than appears at first sight.

The main features of the standard record proposed in the Report are:-

1 A standard gusseted folder with a simple clip-less metal strip fastening.

2 A standard size of paper, for which the International A4 size ( $8 \frac{1}{4}$ in. $\times 11 \frac{3}{4}$ in.), one of a relatively new size range increasingly widely used for many purposes, is proposed. With a $\sqrt{ } 2$ side ratio the shape is unchanged after folding in half. It is taller than most hospitals' present paper size (usually about 8 in. $\times 10 \frac{1}{2}$ in. or 11 in.) and may cause difficulties in filing, but the decision seems otherwise unimpeachable. The smaller A5 and A6 sizes (half and quarter respectively of the A4) will be used for smaller documents where possible.

3 An identification sheet, which includes all the usual particulars of patients, with details of identification, admission, discharge, diagnosis, operations, or the like. The essential and valuable novelty is that it is arranged for convenient coding, and it is assumed that if the pattern is standard most of the central returns and statistics laboriously produced by hand by every hospital can be dealt with simply by handing on a carbon of the form to a central office where they can be coded and analysed by computer.

4 A variety of more or less straightforward clinical documents-history sheet, discharge summary, discharge letter, general practitioner's letter, mount sheet, nursing record, temperature chart, and the like-most of them plain and unexceptionable versions of documents on whose exact design no two clinicians will ever agree wholly. More original and controversial proposals include a rather elaborate drug sheet and a "communications' sheet, but these can be left to the clinicians to argue about.

\section{LABORATORY AND OTHER REPORT FORMS}

The Report endorses the general trend towards the use of report forms gummed to a full-sized mount sheet. It accepts roof-tile mounting, with the report forms gummed along the top and overlapping from below upwards. (The alternative side gumming, so much more attractive in many ways, is bad in practice: the solid strip of overlapping gummed edges up the side of the mount sheet is stiff and heavy and liable to peel off in a mass after a few months.) A standard size for all reports ( $x$-ray, etc., as well as laboratory) is recommended: no International size is suitable and $7 \frac{1}{2}$ in. $\times 5$ in. is proposed, but the alternative of the smaller A6 size ( $5 \frac{7}{8}$ in. $\times$ $4 \frac{1}{8}$ in.) is suggested as suitable for use in some circumstances. A colour code for the laboratories is suggested, and a sample histology report form is indicated. The latter is unsatisfactory in several respects: in particular, the lower edge that is exposed in the roof-tile system, which is the place where it is necessary to have the means of rapid identification of the individual report (the date and site, most often) is entirely occupied by the word 'histology', an enormous colour flash, and the clinician's name (the pathologist's signature, which is too often in other patterns all that shows at the bottom of the report in this system, is at least a marginally better means of identification than this.)

There is nothing at all on standardization of request forms in the Report.

A SEMI-OFFICIAL COMMENT FROM THE ASSOCIATION OF CLINICAL PATHOLOGISTS

The A.C.P. of course knew nothing officially of the terms of the Report until its publication. But the Council had been asked for its views by a Scottish committee which is engaged in producing its own version of the Tunbridge proposals. The Council appointed a committee under the chairmanship of Dr. A. G. Signy to look into the matter. They found themselves in remarkably close agreement with the Scottish committee in welcoming the Tunbridge proposals, but suggested some small but vital changes, which have since been accepted by the Scottish committee.

Only one size and style of report form should be accepted for every reporting department. Top-gumming must be standard. The width may vary a little, but height cannot vary by more than about $t$ in. without 
risk of the smaller form being completely overlapped and hidden by the larger. The number of reporting departments in one hospital, and the number of hospitals covered by one laboratory (some highly specialized laboratories in effect report to the whole country) steadily grows, and the only real answer is the firm adoption of a single size throughout the hospital service. For a few special purposes (post-mortem reports, E.C.G.s, and the like) a full-sized sheet (A4) is necessary, but apart from this all reports, even from the most specialized and ephemeral departments, should be of the one size.

The Tunbridge size is too big (too wide, for instance, for comfortable mounting on its own mount sheet) and the committee believes that 7 in. $\times 4 \frac{1}{3}$ in. is the right compromise. (The $4 \frac{1}{3}$ in. height enables three to go to a foolscap sheet, which is convenient for some popular forms of duplication.)

The forms should be redesigned to take account of the need to make the specimen identification visible on the exposed lower margin.

Some consideration should be given to the standardization of request forms. That this should be mentioned at all from the laboratory side is evidence of altruism, for standardization here will often lead to more radical interference with the laboratory's internal record system than will standardization of report forms. But it already been shown by several hospitals that it is possible to use a single request form for many departments. He again standardization would bring great advantages to laboratories that receive specimens from many outsigde hospitals. This is perhaps a reform for which the groutind has not been well enough prepared for there to be $\frac{5}{x}$ expectation of rapid acceptance, but it is one about which pathologists should be thinking, and the subject is ane which the Tunbridge Report might well have touched upon.

It is to be hoped that on the whole pathologists $\overrightarrow{\mathrm{v}}$ ll welcome the Tunbridge Report, and do their best to seegfs proposals brought into effect, after due allowance for the special local circumstances which require local mợlifications. In respect of the report forms, which are aspect which most particularly concerns their own labioratories, could it be suggested that they hold their haipd for the moment until it can be determined whether the arguments of the A.C.P. committee and the Scottsh committee lead to any change in the Tunbridge proposals? Once however it is clear that a size and style of repert form is definitely decided upon, it is to be hoped that every laboratory will proceed as rapidly as possible ${ }^{\circ}$ conform to the standard.

\section{Reports and Bulletins prepared by the Association of Clinical Biochemists}

The following reports and bulletins are published by the Association of Clinical Biochemists. They may be obtained from Mr. J. T. Ireland, Biochemistry Laboratory, Alder Hey Children's Hospital, Liverpool, 12. The prices incluffe postage, but airmail will be charged extra.

\section{SCIENTIFIC REPORTS}

1 Colorimeters with Flow Through Cells. A Critical Assessment of 4 Instruments. 1965. P. M. G. BROUGHTON and C. RILEY. $13 \mathrm{~s} 6 \mathrm{~d}$.

\section{TECHNICAL BULLETINS}

1 Data Sheet on Control Sera. July 1964. 1s.

2 A Report on the Enzyme Questionnaire Circulated by the Scientific Committee. December 1964. A. H. GOWENLOCK. $1 \mathrm{~s}$.

3 Non-recording Spectrophotometers for the Visible and Ultraviolet Ranges. A comparative table of instru- ments available in Great Britain. May 1965. A.角. GOWENLOCK, P. C. NICHOLAS, and J. H. WILKINS\&. 1s. $6 \mathrm{~d}$.

4 Control Solutions for Clinical Biochemistry. Juำ 1965. P. M. G. BROUGHTON and A. H. GOWENLOG. 1s. $6 \mathrm{~d}$.

5 Recording Spectrophotometers. A comparative list $\mathrm{Nf}_{\mathrm{f}}$ low-priced instruments readily available in Britaino. July 1965 . P. SEWELL. 2s. 6d.

6 A guide to Automatic Pipettes. A list of more than 100 instruments compiled from manufacturers' literatuke. August 1965. P. M. G. BROUGHTON. 5s.

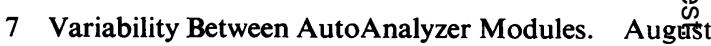
1965. B. E. NORTHAM. 1s 6d. 